\title{
PRÁTICAS ALTERNATIVAS, COMPLEMENTARES E INTEGRATIVAS EM SAÚDE NA CIDADE DE CAMPINA GRANDE-PB: CARACTERIZAÇÃO DO SETOR PRIVADO DE PRESTAÇÃO DE SERVIÇOS
}

\author{
ALTERNATIVE, COMPLEMENTARY AND INTEGRATING PRACTICES IN HEALTH IN THE CITY \\ OF CAMPINA GRANDE - PB: CHARACTERIZATION OF THE PRIVATE SERVICE PROVISIONS
}

\author{
Martha Priscila Bezerra Pereira \\ Doutora em Geografia, UFCG) \\ mpbcila@yahoo.com.br \\ Gabriel Eloi Marinho \\ graduando em Geografia, UFCG) \\ gabrieleloimarinhsouto@hotmail.com \\ Paulo Ginjo Afuso \\ graduando em Geografia, UFCG) \\ paulogafuso@bol.com.br
}

\begin{abstract}
RESUMO
As práticas alternativas, complementares e integrativas em saúde estão presentes no espaço geográfico brasileiro desde pelo menos a segunda metade do século XX. A partir de 2006, com a aprovação da Política Nacional de Práticas Integrativas e Complementares, essas formas de cura passaram a ter respaldo legal, sendo reconhecidas paulatinamente pelos estados e municípios. Em Campina Grande, essa política está tramitando na Câmara Municipal de Campina Grande (2018) estando este tipo de atividade presente no município através do setor privado. Desta forma, este trabalho tem por objetivo analisar as práticas alternativas, complementares e integrativas em saúde em Campina Grande - PB no setor privado de prestação de serviços. Para viabilizar este estudo seguiram-se os seguintes procedimentos: a) levantamento de referências; b) levantamento documental; c) Trabalho de campo exploratório; d) Trabalho de campo; e) Elaboração de um banco de informações; f) Espacialização dos serviços; g) Análise das práticas ACl em Campina Grande. Como resultados principais, percebeu-se que tais práticas estão presentes principalmente nos procedimentos individuais; a introdução desta atividade provocou uma mudança funcional do serviço dentro do espaço urbano tornando mais complexa a oferta de serviços a partir de novas atividades e; segregou o acesso da parcela mais carente da população.
\end{abstract}

Palavras-chave: PNPIC. Cidade. Geografia da Saúde.

\begin{abstract}
Alternative, complementary and integrative health practices have been present in Brazilian geographical space since at least the second half of the 20th century. Starting in 2006, with the approval of the National Policy on Integrative and Complementary Practices, these forms of healing became legally supported, being gradually recognized by the states and municipalities. In Campina Grande, this policy is being carried out in the City Hall of Campina Grande (2018) and this type of activity is present in the municipality through the private sector. In this way, this work aims to analyze alternative, complementary and integrative practices in health in Campina Grande - PB in the private service sector. To
\end{abstract}

\footnotetext{
${ }^{1}$ Este trabalho apresenta os resultados da iniciação científica (PIBIC/PIVIC - UFCG) realizada no período entre 2017 e 2018 e foi apresentado IX Simpósio Nacional de Geografia da Saúde, Blumenau, SC, 2019.
}

Recebido em: 13/10/2019

Aceito para publicação em: 11/11/2019 
make this study viable, the following procedures were followed: a) survey of references; b) documentary survey; c) Exploratory fieldwork; d) Fieldwork; e) Elaboration of an information bank; f) Spatialization of services; g) Analysis of ACI practices in Campina Grande. As main results, it was realized that such practices are present mainly in the individual procedures; the introduction of this activity led to a functional change of service within the urban space, making the offer of services more complex from new activities; segregated the access of the most deprived part of the population.

Key-words: PNPIC. City. Health Geography.

\section{INTRODUÇÃO}

A partir das últimas décadas do século $X X$, com a emergência do paradigma da promoção da saúde a partir do ano 1974 com o relatório Lalonde (LALONDE, 1974; LUZ, 2009) e da revalorização das práticas da medicina tradicional e da valorização da Atenção Primária em Saúde, a partir de 1978 (OMS, 1978) a Medicina Tradicional passou por algumas modificações interculturais e denominacionais (medicina alternativa, complementar, integrativa) (BARROS, SIEGEL, OTANI, 2011) para se adequar a outras culturas e à medicina científica.

Em 2002, com a publicação da Organização Mundial de Saúde intitulada "Estratégia da OMS sobre Medicina Tradicional 2002-2005" (OMS, 2002) houve maior impulso para que no Brasil fosse implantada uma política relacionada ao tema.

Em 2006 é implantada a Política Nacional de Práticas Integrativas e Complementares que trata de recomendar no seu art. 1, parágrafo único, "a adoção, pelas Secretarias de Saúde dos Estados, do Distrito Federal e dos Municípios, da implantação e implementação das ações e serviços relativos às Práticas Integrativas e Complementares" (BRASIL, 2006, p. 1-2).

A partir do ano de 2006 vários estados aderiram, e paulatinamente municípios (BRASIL, 2011), porém esta adesão pelo Sistema Único de Saúde (SUS) não abrange ainda todos os municípios, como é o caso de Campina Grande - PB (SOUSA, 2014; CAMPINA GRANDE, 2017), ficando esta prática a depender principalmente da iniciativa privada.

Desta forma, este trabalho tem como objetivo analisar as práticas alternativas, complementares e integrativas em saúde em Campina Grande - PB no setor privado de prestação de serviços.

Este artigo foi enviado inicialmente como trabalho completo para o IX Simpósio Nacional de Geografia da Saúde, ocorrido em Blumenau - SC entre 19 a 21 de junho de 2019 com o título "Práticas alternativas, complementares e integrativas em saúde na cidade de Campina Grande - PB" e foi selecionado como um dos melhores do eixo "Práticas complementares/alternatividades em saúde".

Além desta introdução e das considerações finais o texto foi subdividido em seis partes. $\mathrm{Na}$ metodologia foram apresentados todos os procedimentos utilizados na pesquisa. Na fundamentação teórica foram trabalhados os principais conceitos e apresentada a escala enquanto teoria para auxiliar no entendimento da problemática estudada. Na terceira parte Caracterização das práticas foi apresentada a combinação do resultado das leituras e do trabalho de campo realizado em que foi possível realizar a espacialização de todos os estabelecimentos em atividade entre 2017 e 2018 . Nos itens Perfil dos terapeutas e Perfil dos usuários foi realizada uma caracterização destes grupos na cidade. Por fim, as práticas alternativas, complementares e integrativas em saúde no SUS: uma possibilidade de melhoria deste serviço, trouxe as ações que estão sendo realizadas no sentido de implantar uma política municipal em Campina Grande que até julho de 2019 continua no processo de avaliação na Câmara Municipal de Campina Grande - PB. 


\section{METODOLOGIA}

Para esta pesquisa foram realizadas as seguintes etapas: a) levantamento de referências; b) levantamento documental; $\mathrm{c}$ ) trabalho de campo exploratório (análise geral da paisagem externa, coleta da coordenada geográfica); d) trabalho de campo (aplicação de formulário, registro fotográfico e coleta de informações em fichas/prontuários); e) elaboração de um banco de informações; f) espacialização dos serviços e; g) análise das práticas ACl em Campina Grande.

No que diz respeito ao levantamento de referências foram consultados artigos e livros relacionados às práticas alternativas, complementares e integrativas em saúde, dentre os principais destacaram-se Rosenfeld (1999), Barros (2008), Luz (2009) e Brasil (2018a); em relação à fundamentação teórica destacaram-se Santos (2014), Pereira (2018) e Souza (2015) e em relação à metodologia foram utilizados principalmente Braun (2008) e Bossle (2016; 2017).

Em relação ao levantamento documental foram consultados relatórios e a legislação relacionada à problemática estudada, dentre os mais importantes estão o Relatório de Gestão sobre Práticas Integrativas e Complementares no SUS - 2006-2010 (BRASIL, 2011), a Política Nacional de Práticas Integrativas e Complementares (BRASIL, 2006) e as portarias 849 (BRASIL, 2017b) e 702 (BRASIL, 2018b) que tratam da inclusão práticas.

No trabalho de campo exploratório foi realizada uma observação geral da paisagem e sua localização dentro do contexto da cidade, além de coletadas as coordenadas geográficas. Neste momento foi possível observar atividades realizadas no entorno e como estavam organizadas no contexto da cidade. $\mathrm{Na}$ parte externa foram observados os seguintes elementos: iluminação pública, ruídos, acessibilidade externa (vagas de estacionamento, presença de rampas, jardim, sinalização, segurança) e localização na cidade (circulação de pessoas, proximidade a outros empreendimentos, acesso fácil a grandes avenidas e proximidade a parada de ônibus).

No trabalho de campo foram realizadas coletas de informações através da aplicação de formulários aos terapeutas (gênero/ formação/local onde morou a maior parte da vida/origem dos produtos para terapêutica/classe social predominante atendida/bairros de origem dos usuários/autoclassificação enquanto terapeuta/opinião da implantação desta terapia pelo SUS, entre outras perguntas) e coletadas informações das fichas de seus pacientes/alunos/clientes (motivo inicial da procura/primeira queixa principal/bairro ou localidade da moradia/diagnóstico/prescrição ou orientação). Além da observação da paisagem interna do estabelecimento a partir dos seguintes elementos: luminosidade (natural, artificial, inexistente); flora (natural, artificial, inexistente), ruídos (ausente, flutuante ou contínuo), música ambiente (tranquila,agitada ou ausente); organização das atividades (presença suficiente de funcionários, sinalização, atendimento prioritário, organização dos cômodos).

O banco de informações foi elaborado com base nas informações coletadas em campo, sendo possível fazer a espacialização das práticas utilizando o software livre Qgis, versão 2.18. A análise foi realizada a partir dessas informações e das leituras realizadas sobre o tema.

Vale salientar que estas pesquisas foram aprovadas pelo Comitê de Ética e Pesquisa, tendo como números identificadores: 78556917.1.0000.5182 (Análise das práticas alternativas, complementares e integrativas em saúde em Campina Grande - PB) e 78605317.4.0000.5182 (Expansão das práticas alternativas, complementares e integrativas em saúde no município de Campina Grande - PB).

\section{FUNDAMENTAÇÃO TEÓRICA}

A partir dos fundamentos apresentados por Pereira (2018) pode-se trabalhar com a escala geográfica enquanto teoria, uma vez que os eventos ocorridos em um município refletem influências externas de localidades de mesmo porte e de escalas geográficas mais distantes como o país e outros locais no mundo, assim como são trazidas ideias dessas escalas geográficas que se concretizam em ações, modificando também os objetos dentro de um município.

Concordando com Souza (2015) em que o conceito de escala geográfica seria "a própria extensão ou magnitude do espaço que se está levando em conta" pode-se trabalhar com o jogo escalar no sentido de entender que práticas integrativas estariam sendo apropriadas de escalas distantes e trazidas à cidade de Campina Grande (apropriação de ideias existentes); os depoimentos de pessoas e/ou empresários de outras cidades que relatam que determinada prática tem sido eficaz, seja DOI:http://dx.doi.org/10.14393/Hygeia153351665 Hygeia 15 (33): $54-66$, Set/2019 página 56 
enquanto atividade, seja enquanto negócio (experiências locais exitosas); o quanto a permissão da legislação federal auxilia determinado profissional a optar por investir em uma prática natural e/ou holística (normatização do território) e por último; o processo de ajuda mútua entre bairros, ou cidades na implantação de determinada prática, que pode ocorrer em ocasião posterior, ou em um mesmo momento (território-rede).

Essas ações fazem surgir alguns tipos de paisagem: a paisagem do risco (por falta de conhecimento aprofundado ou charlatanismo, tendo como consequência semblantes de pessoas amedrontadas ou marcadas por algum erro de procedimento); a paisagem da cura (a partir dos limites e potencialidades de cura de cada uma dessas práticas, estando presente na paisagem através de semblantes e elementos resultantes da ação de pessoas que recuperaram a saúde e voltam a realizar suas atividades cotidianas); a paisagem da prevenção (devido modificação de atitudes e hábitos, tendo como elementos na paisagem objetos que demonstrem algum cuidado para não contrair determinada morbidade) e; paisagem da promoção da saúde (a partir do indivíduo, quando os hábitos foram internalizados e melhoram a qualidade da saúde e de vida do indivíduo, família e sociedade como um todo e a partir do Estado, quando passa a agir a partir de um entendimento voltado para a saúde, estando presentes na paisagem elementos que demonstrem ações de que foi realizado algo para um bem estar geral) (PEREIRA, 2010; 2018).

\section{CARACTERIZAÇÃO DAS PRÁTICAS}

No que diz respeito às práticas presentes no setor privado em Campina Grande - PB foram identificadas tanto as práticas naturais, consideradas como métodos, técnicas e princípios, conhecimentos ou leis naturais que visam a normalização das pessoas (CARIACICA, 2015) quanto as holísticas, que seriam terapias que buscam integrar a pessoa tanto individualmente quanto coletivamente (PAIVA, 2004; SIGNIFICADOS, 2018). As práticas presentes em Campina Grande identificadas na pesquisa (2017-2018) foram: acupuntura e tai chi chuan (China); Muay thai (Tailândia); medicina antroposófica (Áustria); ayurveda e yoga (Índia); shiatsu e jiu jitsu (Japão); Homeopatia e Pilates (Alemanha), osteopatia e quiropraxia (EUA) e; neopilates (Brasil) (BRASIL, 2006, 2015, 2017b; BRAZ, 2014; DEVEZA, 2013; LOT, 2008; MASSELI, TURATI, CRUZ, SILVESTRE e PEREIRA, 2010; NEVES, 2016; ROBBE, 2006 APUD ARRUDA E SOUZA, 2017; GOMES ET AL APUD SILVEIRA, MAZZOCCANTE, SOUSA, OLHER, MENDES, ASANO, 2013; ROSENFELD, 1999; TARCITANO FILHO \& WAISE, 2016; VEIGA, 2016) (quadro 1). Destas práticas, nem todas estão incluídas na política federal como é o caso do tai chi chuan, muay thai, shiatsu, jiu jitsu, pilates e neopilates, mas podem ser consideradas terapias naturais e/ou holísticas. Essas práticas tem origem na Ásia, Europa e mais recentemente, na América. A maioria busca entender o processo saúde-doença de maneira holística e/ou natural. A partir da caracterização foi possível espacializar essas práticas na cidade de Campina Grande (mapa 1).

Quadro 1: Categorização das práticas por país de origem na forma como se apresenta na atualidade

\begin{tabular}{|c|c|l|c|}
\hline $\begin{array}{c}\text { PAÍS DE } \\
\text { ORIGEM NOS } \\
\text { MOLDES } \\
\text { ATUAIS }\end{array}$ & PRÁTICA & \multicolumn{1}{|c|}{ INFORMAÇÕES SOBRE A PRÁTICA } & REFERÊNCIA \\
\hline \multirow{3}{*}{ Alemanha } & Homeopatia & $\begin{array}{l}\text { A homeopatia começou a se propagar pelo } \\
\text { mundo logo após sua formulação por Samuel } \\
\text { Hahnemann (1755-1843), na futura Alemanha, na } \\
\text { primeira década do século XIX. Na homeopatia, o } \\
\text { adoecimento é a expressão da ruptura da } \\
\text { harmonia das dimensões física, psicológica, } \\
\text { social e cultural. }\end{array}$ & $\begin{array}{c}\text { FILHO \& WAISE, } \\
\text { (TARCITANO } \\
\text { 2006) }\end{array}$ \\
\cline { 2 - 5 } & Pilates & $\begin{array}{l}\text { É um método de exercício que consiste na } \\
\text { utilização de seu próprio corpo e alguns outros } \\
\text { objetos para fortalecer, relaxar e corrigir a postura }\end{array}$ & (LOT, 2008) \\
\hline
\end{tabular}




\begin{tabular}{|c|c|c|c|}
\hline & & do usuário. & \\
\hline Áustria & $\begin{array}{c}\text { Medicina } \\
\text { Antroposófica }\end{array}$ & $\begin{array}{l}\text { É uma medicina de base vitalista com modelo de } \\
\text { atenção transdisciplinar. Destaca-se pelo uso de } \\
\text { medicamentos homeopáticos, fitoterápicos e } \\
\text { próprios da Medicina Antroposófica. Além do } \\
\text { diagnóstico convencional, busca-se um } \\
\text { entendimento do paciente de forma mais } \\
\text { holística. Além dos medicamentos há os recursos } \\
\text { terapêuticos não medicamentosos como: } \\
\text { aplicações externas, banhos terapêuticos, } \\
\text { massagem rítmica e terapia artística. }\end{array}$ & $\begin{array}{c}\text { (BRASIL, 2006; } \\
\text { 2015) }\end{array}$ \\
\hline Brasil & Neopilates & $\begin{array}{l}\text { É um pilates aprimorado com o foco de deixar ele } \\
\text { mais divertido e atualizado. Ele une o pilates } \\
\text { convencional ao treinamento funcional e de circo. }\end{array}$ & (BRAZ, 2014). \\
\hline \multirow[t]{2}{*}{ China } & Acupuntura & $\begin{array}{l}\text { Inicialmente faz-se o diagnóstico através da } \\
\text { língua, do pulso e do seu contexto de vida } \\
\text { relatado pelo paciente, isso determina o grau de } \\
\text { desequilíbrio yin e yang e de fluidez do chi. } \\
\text { Depois desta etapa é que se definem os } \\
\text { meridianos e quais os pontos devem ser } \\
\text { agulhados ou não. }\end{array}$ & $\begin{array}{c}\text { (ROSENFELD, } \\
1999)\end{array}$ \\
\hline & Tai chi chuan & $\begin{array}{l}\text { Arte marcial milenar, consiste em movimentos } \\
\text { com o corpo, neste caso, desarmado, em busca } \\
\text { de uma extrema concentração e autocontrole, } \\
\text { fortalece o corpo, melhora a postura e a } \\
\text { respiração. }\end{array}$ & $\begin{array}{l}\text { (BRASIL, 2017b; } \\
\text { XAVIER, 2016) }\end{array}$ \\
\hline $\begin{array}{l}\text { PAÍS DE } \\
\text { ORIGEM NOS } \\
\text { MOLDES } \\
\text { ATUAIS } \\
\end{array}$ & PRÁTICA & INFORMAÇÕES SOBRE A PRÁTICA & REFERÊNCIA \\
\hline \multirow[b]{2}{*}{ EUA } & Osteopatia & $\begin{array}{l}\text { "As disfunções da mobilidade articular e teciduais } \\
\text { em geral contribuem no aparecimento das } \\
\text { enfermidades. A abordagem esteopática envolve } \\
\text { o profundo conhecimento anatômico, fisiológico e } \\
\text { biomecânico global, (...) para que o próprio } \\
\text { organismo busque equilíbrio/homeostase" }\end{array}$ & $\begin{array}{c}\text { (BRASIL, 2017b } \\
\text { p.5) }\end{array}$ \\
\hline & Quiropraxia & $\begin{array}{l}\text { A história conta que a quiropraxia surge de forma } \\
\text { inusitada. Surgiu na cidade de Davenport em } \\
\text { lowa no ano de } 1895 \text { através do dr. Palmer. } \\
\text { Nesta época trabalhava como terapeuta } \\
\text { magnético e dentro do seu consultório tinha um } \\
\text { funcionário que era surdo há } 17 \text { anos devido um } \\
\text { acidente. Palmer pediu para analisar a coluna } \\
\text { dele e logo mais percebeu uma vértebra fora do } \\
\text { lugar, então usando as mãos colocou-a no lugar. } \\
\text { Há relatos de que o homem voltou a ouvir depois } \\
\text { desse procedimento. Nesse contexto Palmer } \\
\text { levantou a hipótese de que ossos fora dos locais } \\
\text { corretos podem causar diversos problemas de } \\
\text { saúde. }\end{array}$ & (NEVES, 2016) \\
\hline Índia & ayurveda & $\begin{array}{l}\text { Ayurveda como doutrina unificada e organizada } \\
\text { surge por volta do século V a.C.. A palavra } \\
\text { significa literalmente "conhecimento ou ciência } \\
\text { (veda) da longevidade (ayus). Sua difusão } \\
\text { ocorreu devido às várias invasões e fugas do } \\
\text { povo indiano. Para eles o progresso de } \\
\text { manifestação das doenças ocorre em seis }\end{array}$ & (DEVEZA, 2013) \\
\hline
\end{tabular}




\begin{tabular}{|c|c|c|c|}
\hline & & $\begin{array}{l}\text { estágios evolutivos que iniciam pelas } \\
\text { manifestações dos humores nos seus locais } \\
\text { preferenciais no sistema digestório , até sua } \\
\text { localização com comprometimento de órgãos } \\
\text { vitais. Ao observar esses estágios é possível } \\
\text { identificar a forma adequada de tratamento que, } \\
\text { para isso, a primeira coisa que se busca é } \\
\text { entender os mecanismos físicos e mentais que } \\
\text { levaram os indivíduos a alterarem essas funções } \\
\text { e inicialmente corrigir a rotina diária (dinacharya) } \\
\text { para impedir que novos produtos tóxicos (Ama) } \\
\text { sejam formados.l Ou seja, o contraponto com a } \\
\text { medicina tradicional é que o foco não é a doença, } \\
\text { mas o que gerou a doença em aspectos } \\
\text { multilaterais. E além de corrigir aquela falha, } \\
\text { trabalha preventivamente a educação alimentar, } \\
\text { emocional e espiritual. }\end{array}$ & \\
\hline $\begin{array}{l}\text { PAÍS DE } \\
\text { ORIGEM NOS } \\
\text { MOLDES } \\
\text { ATUAIS }\end{array}$ & PRÁTICA & INFORMAÇÕES SOBRE A PRÁTICA & REFERÊNCIA \\
\hline Índia & yoga & $\begin{array}{l}\text { Algumas pessoas consideram o yoga como uma } \\
\text { filosofia de vida, não somente um exercício. } \\
\text { Enquanto filosofia o yoga é um estilo de vida no } \\
\text { qual se busca estar bem com a vida e nós } \\
\text { mesmos. De forma histórica deriva das tradições } \\
\text { hindus e no sânscrito (que é a língua datada de } \\
5.000 \text { anos a.C possuindo mantras e textos } \\
\text { sagrados) estando extremamente relacionada a } \\
\text { questões religiosas. Todavia, se os usuários não } \\
\text { quiserem se envolver com tais práticas o corpo } \\
\text { continuará sendo beneficiado com os exercícios } \\
\text { que estimulam a elasticidade, controle da } \\
\text { respiração, ajudando no alívio de estresse, por } \\
\text { exemplo. }\end{array}$ & (VEIGA, 2016) \\
\hline \multirow[t]{2}{*}{ Japão } & jiu jitsu & $\begin{array}{l}\text { Conjunto de técnicas asiáticas que foram melhor } \\
\text { desenvolvidas no Japão e se caracteriza como } \\
\text { luta com agarre, com técnicas específicas de } \\
\text { projeções, imobilizações e finalizações. }\end{array}$ & $\begin{array}{c}\text { (ROBBE, } 2006 \\
\text { APUD ARRUDA E } \\
\text { SOUZA, 2014; } \\
\text { GOMES ET AL, } \\
2010 \text { APUD } \\
\text { SILVEIRA, ET AL, } \\
2013)\end{array}$ \\
\hline & shiatsu & $\begin{array}{l}\text { Esta técnica utiliza a pressão das mãos em } \\
\text { determinados pontos do corpo para ajustar a } \\
\text { estrutura física e suas energias intrínsecas para } \\
\text { prevenir doenças ou até promover a saúde. }\end{array}$ & $\begin{array}{l}\text { (MASSELLI, } \\
\text { TURATTI, CRUZ, } \\
\text { SILVESTRE, } \\
\text { PEREIRA, 2010) }\end{array}$ \\
\hline Tailândia & Muay thai & $\begin{array}{l}\text { Inicialmente era para ser uma arte marcial, } \\
\text { porém, como acaba desenvolvendo um } \\
\text { fortalecimento muscular passou a ser entendido } \\
\text { como esporte, lazer e uma forma de cuidado com } \\
\text { a saúde. }\end{array}$ & $\begin{array}{l}\text { (SANTOS, DA } \\
\text { VEIGA, 2012) }\end{array}$ \\
\hline
\end{tabular}


Mapa 1: Terapias naturais e holísticas incluídas ou não na Política Nacional de Práticas Integrativas e Complementares (PNPIC) na Cidade de Campina Grande-PB por densidade

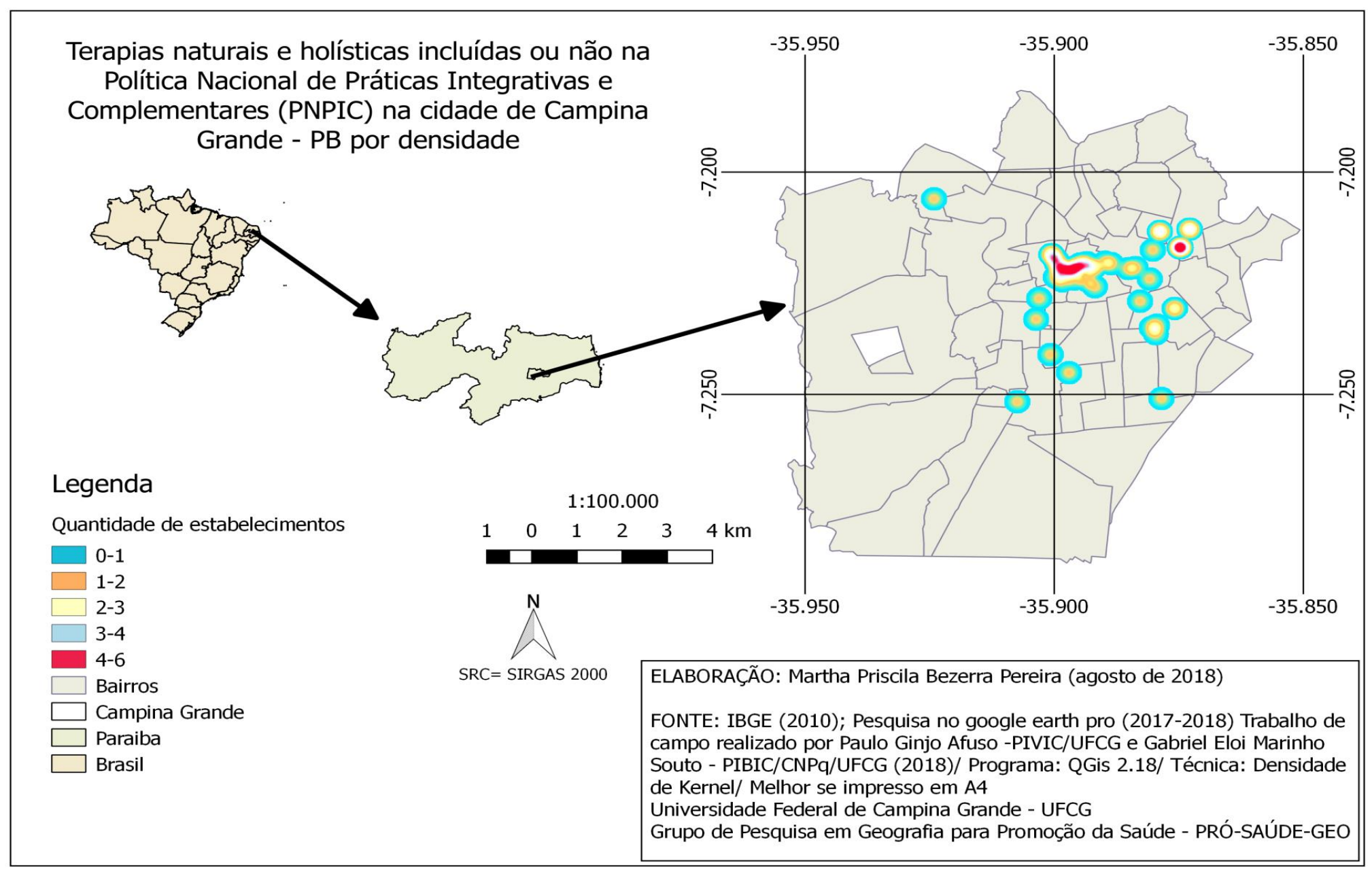


Percebeu-se que tais práticas estão presentes no setor privado principalmente nos procedimentos individuais, nas áreas em que há grande circulação de pessoas ou mesmo em que a população tem melhor renda para pagar por este serviço. Estes serviços estão principalmente na porção centro-leste da cidade.

Os bairros que concentram a maior parte dos serviços são: Prata, Bela Vista, Centro e Catolé. Nos bairros de Bela Vista e Centro, estes serviços estão nas áreas de maior circulação. Já em relação aos bairros da Prata e Catolé, além de estarem em locais de maior circulação, também estão localizados onde há um maior número de pessoas com renda média superior ao salário mínimo.

As práticas mais presentes são a acupuntura e o pilates. A partir do resultado do trabalho de campo foi possível entender que as práticas estão presentes devido a uma apropriação de ideias de outras escalas geográficas e, ao mesmo tempo, sofrem influência das ideias que são sugeridas de maneira proativa pelas instituições internacionais como Organização Mundial da Saúde (OMS) e Organização Panamericana de Saúde (OPAS). Além disso, há uma rede de relações entre profissionais que agem como militantes de suas ideias de forma individual, divulgando resultados a partir de relatos de experiência, mas que podem ser entendidos como sujeitos coletivos por refletirem ideias de um grupo social que pretende implantar essas práticas em todas as instâncias possíveis, entre elas hospitais e creches.

Quanto à essa situação, segundo Vilaça (2001), houve uma mudança funcional do serviço dentro do espaço urbano, fazendo com que se tornasse mais complexa a oferta de serviços a partir dessas atividades, porém, como observado em campo, não houveram mudanças significativas nas fachadas dos estabelecimentos ao ponto de se observar um novo paradigma da saúde.

\section{PERFIL DOS TERAPEUTAS}

Dos trinta e seis (36) estabelecimentos identificados na cidade, foi possível aplicar formulários a vinte e quatro (24) terapeutas e a quarenta e cinco (45) usuários.

Foi identificado que existe uma predominância de mulheres, tanto no atendimento inicial (fruto da observação em campo) quanto em relação ao profissional que atende (76\% são mulheres).

A maior parte dos terapeutas morou predominantemente na área urbana $(82 \%)$, seguido de $18 \%$, que morou em ambiente rural por parte significativa de sua vida.

Outra questão a ser considerada é a autoclassificação do profissional, eles tiveram dificuldade de se autoclassificar, porém, após explicação dos significados de cada conceito (alternativo, complementar e integrativo), $6 \%$ se considerou alternativo, $65 \%$ como complementar e $29 \%$ como integrativo (gráfico 1).

\section{Gráfico 1}

\section{como se autoclassifica os terapeutas}

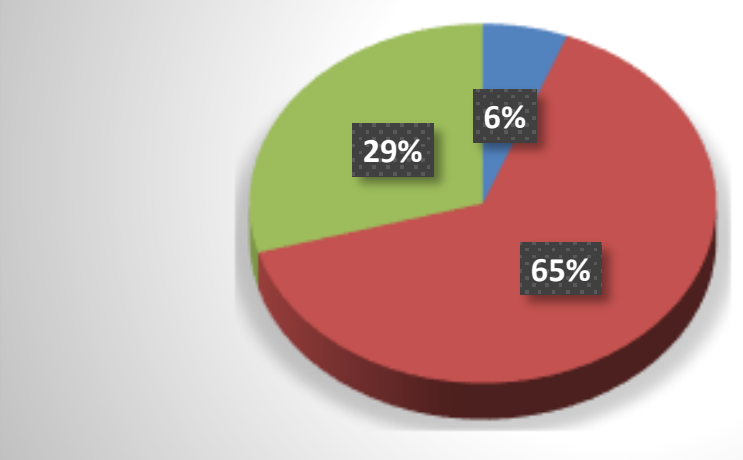

$$
\text { alternativo }
$$

complementar

integrativo

Fonte: Trabalho de campo realizado entre janeiro e fevereiro de 2018. 
Para situar melhor o leitor, as diferenças entre Medicina tradicional, alternativa, complementar e integrativa são históricas, surgiram no movimento de reconhecimento em que a Medicina tradicional, originária de determinada cultura passa a denominar-se alternativa para outra. De acordo com Barros, Siegel e Otani (2011), a partir da década de 1980, quando se consolidou o movimento para incorporar essas práticas terapêuticas alternativas aos sistemas médicos oficiais, estas passaram a ser entendidas por alguns como complementar ao sistema existente ou como sinônimo de medicina alternativa. Posteriormente, foram entendidas como integrativa, pois estariam integradas ao sistema de forma interdependente, sento esta a razão do uso destes termos.

Quanto à origem do material utilizado, os mesmos são provenientes de Campina Grande (23\%), João Pessoa (32\%) e São Paulo (45\%). Os materiais são relacionados à acupuntura (gráfico 2).

\section{Gráfico 2}

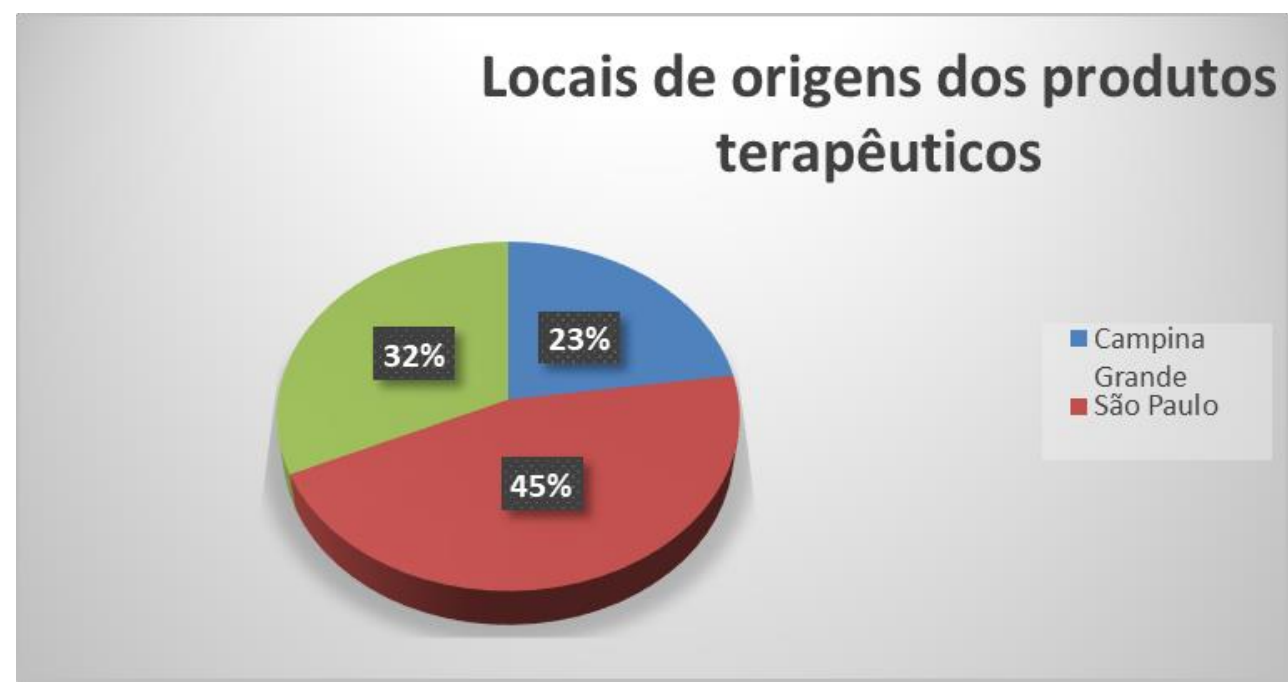

Fonte: Trabalho de campo realizado entre janeiro e fevereiro de 2018.

Também foi perguntado se o estabelecimento tinha algum vínculo com a rede pública, a resposta, como esperado foi que todos os estabelecimentos apenas atendem de forma particular ou por convênios particulares.

\section{PERFIL DOS USUÁRIOS}

As razões para estes usuários procurarem algumas destas práticas são variadas. No grupo das pessoas que tem alguma sintomatologia os principais motivos são as dores lombares (acupuntura $60 \%$ ), dor na coluna devido postura incorreta, associado ao excesso de peso (pilates $20 \%$ ) e alto nível de estresse associado à síndrome do pânico (acupuntura de forma integrada a outros tratamentos 20\%). No grupo das pessoas que buscam prevenir doenças ou promover sua saúde, estas se atraem por essas práticas por sentirem a necessidade de praticar um esporte ou ter um lazer. Com relação à origem do usuário, estes são provenientes principalmente do Catolé $(22,22 \%)$, Prata e Malvinas (cada um com 15,56\%), sendo o restante oriundo de outros bairros (Centro $11,11 \%$, Alto Branco - 8,88\%, Mirante, Jardim Paulistano e José Pinheiro - 6,67\%, São José e Santo Antônio - 2,22) ou cidades vizinhas - 2,22\% (gráfico 3).

Com relação à classe social dos usuários, estes se autoclassificaram como de classe alta $(21 \%)$, média $(67 \%)$ e baixa (12\%). No que diz respeito à essa porcentagem, parte desse usuário da classe baixa é proveniente do bairro das Malvinas, que geralmente utiliza essas práticas como tratamento de algo e não como prática de esporte ou lazer, abandonando a prática assim que sente alguma melhora. 
Outro fator a se considerar é que a maior parte da população usuária pertence à classe média, grupo que sofre intensamente com situações de crise no país. Para exemplificar, nos anos de 2015 e 2016, segundo o IBGE (BRASIL, 2017a), o Produto Interno Bruto (PIB) sofreu uma retração de 3,6\%, o que podemos chamar de crise; essa retração não ficou só na teoria, foram justamente os anos em que muitos terapeutas fecharam as portas ou tiveram drásticas reduções do número de clientes devido a maior parte dos usuários ser da classe média e baixa (79\%). O desemprego ou medo deste e o endividamento, fez com que essas atividades ficassem em segundo plano ou mesmo fossem abandonadas.

\section{Gráfico 3}

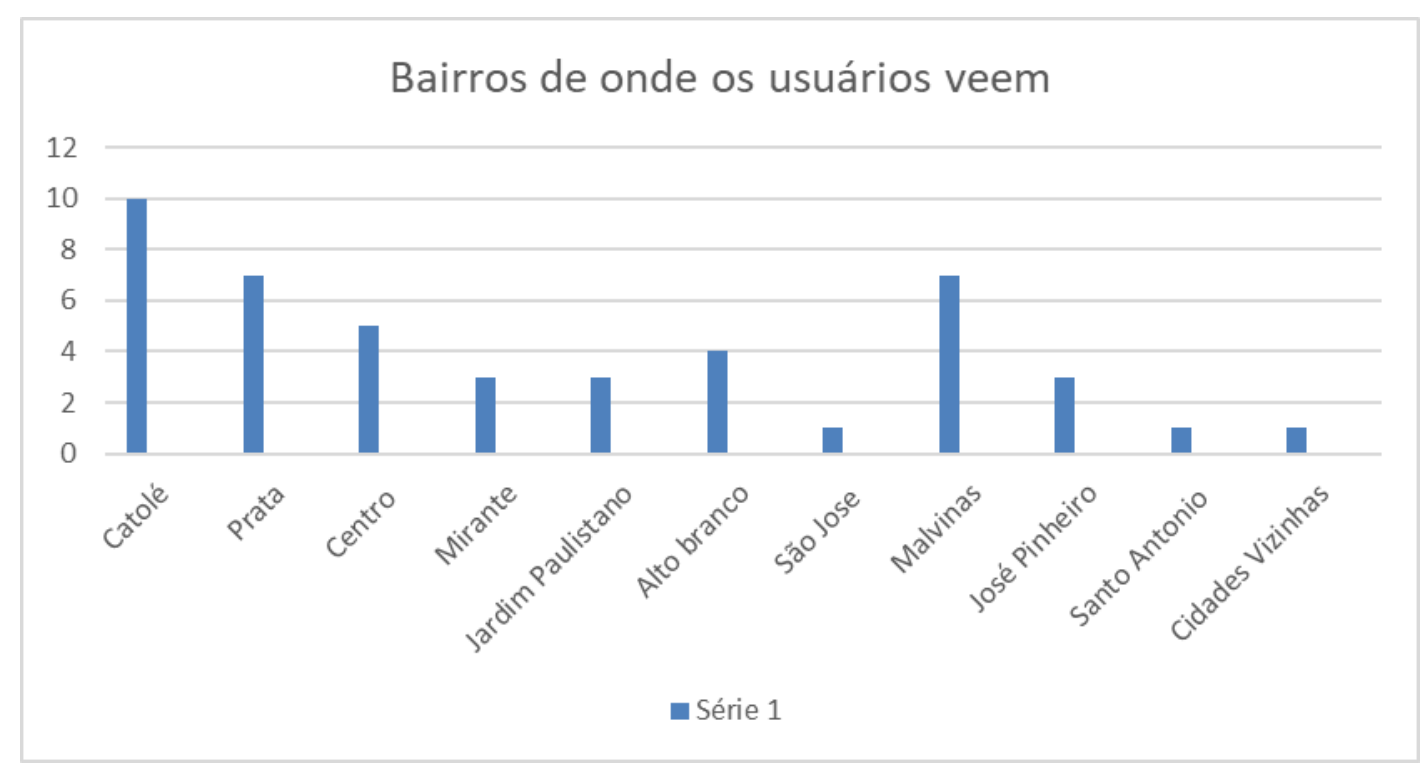

Fonte: Trabalho de campo realizado entre janeiro e fevereiro de 2018.

Um fator que ficou implícito nas respostas dos usuários que ainda frequentam seria a questão geográfica. Resgatando Santos (2014), pode-se entender esse problema quando o autor discute sobre os fluxos e fixos. Os fixos são os prédios que ofertam as práticas, mas também os próximos a eles, já os fluxos são os clientes e as pessoas que passam por lá por alguma razão. Alguns fluxos e fixos podem atuar sobre o espaço favorecendo ou inibindo outros fluxos e fixos. Vale citar o exemplo de uma Academia de Muay Thai que precisou mudar seu endereço porque apesar de estar em um local de grande circulação era também um local com muito ruído, havia dificuldade para estacionar e estava longe de paradas de ônibus, dificultando possíveis usuários da classe média e da classe baixa. Este quadro de referência nos remete a um conjunto complexo de fatores, mas que foram elencados para pesquisas posteriores.

\section{AS PRÁTICAS ALTERNATIVAS, COMPLEMENTARES E INTEGRATIVAS EM SAÚDE NO SUS: UMA POSSIBILIDADE DE MELHORIA DESTE SERVIÇO}

A partir dos resultados obtidos, percebe-se que parte da população usuária tem renda baixa e/ou mora em um bairro que tem uma renda média baixa, essa situação acarreta na necessidade de adesão ao SUS se houver interesse que a população tenha acesso a esse serviço.

Desde o ano de 2017 há o interesse na implantação desta política através do Conselho Municipal de Saúde (CAMPINA GRANDE, 2017), todavia, até 2018 esta política ainda não foi efetivada através de 
um prédio físico e recursos humanos, sendo realizadas de maneira quase informal nas Unidades Básicas de Saúde por médicos e enfermeiros (DANTAS, 2017).

Com essa perspectiva de adesão do município ao SUS em relação às práticas, alguns terapeutas (4\%) temeram esta ideia argumentando que isso faria com que perdessem seus clientes. Porém, considerando os resultados obtidos em relação à faixa de renda, percebe-se que a maior parte da população atendida ( $88 \%$ ) pertence às classes alta e média, estando talvez parte da população com renda mais baixa pretensa a utilizar o serviço pago devido a algum fator específico.

\section{CONSIDERAÇÕES FINAIS}

A localização das práticas alternativas, complementares e integrativas seguiram as regras de mercado em buscar locais com grande circulação de pessoas e que ao mesmo tempo fosse possível o acesso e/ou que estivesse próximo à população com média de renda mais alta. Isso acarretou no aumento da complexificação das funções dentro do espaço urbano de Campina Grande.

O setor privado teve grandes avanços nestes últimos anos. Todavia, na porção de renda mais baixa essas práticas estão presentes de maneira precária em algumas Unidades Básicas de Saúde, que atende a uma porção do território definida e com uma prática específica, ficando essa demanda pendente para grande parcela da população de baixa renda da cidade.

A introdução dessas atividades na cidade faz emergir mais uma vez a discussão sobre possibilidades diversas de cuidado com a saúde, tema que há quase um século parecia ter sido esquecido devido às várias pressões relacionadas à medicina convencional.

\section{REFERÊNCIAS}

ARRUDA, Pablo Delano Porfírio; SOUZA, Bertulino José de. Jiu-jitsu: uma abordagem metodológica relacionada à quebra de estereótipos. Caicó - RN, Redfoco, v.1, n. 1,p.67-89,jan 2014.

BARROS, Nelson Filice de. A construção da medicina integrativa: um desafio para o campo da saúde. São Paulo - SP: Hucitec, 2008.

BARROS, Nelson Filice de; SIEGEL, Pamela; OTANI, Márcia Aparecida Padovan. Introdução. In: BARROS, Nelson Filice de; SIEGEL, Pamela; OTANI, Márcia Aparecida Padovan (org.). O ensino das práticas integrativas e complementares: experiências e percepções. São Paulo - SP. Hucitec, 2011, 171p. P. 15-25.

BOSSLE, Renato Cabral. QGIS do ABC ao XYZ. Curitiba - PR: Edição do autor, 2016, 288p.

BOSSLE, Renato Cabral. QGIS e geoprocessamento na prática. 2.ed. Curitiba - PR: Editora Ithala, 2017, 240p.

BRASIL. Glossário temático: práticas integrativas e complementares em saúde. Brasília - DF: Ministério da Saúde, 2018, 179p. (a)

BRASIL. Pib Brasil 2015/2016. Rio de Janeiro - RJ: Fundação Instituto Brasileiro de Geografia e Estatística, 2017 (a)

BRASIL. Política Nacional de Práticas Integrativas e Complementares no SUS. Brasília - DF: Ministério da Saúde, 2006, 92p.

BRASIL. Política Nacional de Práticas Integrativas e Complementares no SUS. 2.ed. Brasília DF: Ministério da Saúde, 2015, 98p.

BRASIL. Portaria n. 702 de 21 de março de 2018. Brasília - DF: Ministério da Saúde, 2018, 6p. (b) BRASIL. Portaria n. 849 de 27 de março de 2017. Brasília - DF: Ministério da Saúde, 2017, 7p. (b)

BRASIL. Relatório de gestão 2006/2010. Práticas Integrativas e complementares no SUS. Brasília DF: Ministério da Saúde, fevereiro de 2011.

BRAZ, Amanda. Neopilates: pilates + funcional + circo+ funcional. Brasília - DF: Editora Kiron, 2014, $112 p$.

DOI:http://dx.doi.org/10.14393/Hygeia153351665


BRAUN, Ricardo. Novos paradigmas ambientais: Desenvolvimento ao ponto sustentável. 3.ed. Rio de Janeiro: Vozes, 2008, 178p.

CAMPINA GRANDE. Seminário de Terapias Alternativas. Campina Grande: Conselho Municipal de Saúde. Disponível em www.facebook.com/conselhosaudecg/. Acesso em 05 de maio de 2017 (seminário ocorrido em 11/04/2017, das 14 às 17h na Vila do Artesão, em Campina Grande - PB).

CARIACICA. Lei n. 5539 de 11 de dezembro de 2015. Cariacica - ES: Prefeitura Municipal de Cariacica, 2015, 1p.

DANTAS, Miguel. Relação das UBS que possuem em suas rotinas, aplicação das PIC's. Campina Grande - PB: PMCG, 2017, 4p.

DEVEZA, Antônio Cesar Ribeiro Silva. Ayurveda - a medicina clássica indiana. Revista de Medicina. São Paulo - SP, vol. 92, n. 3, p. 156-165, 2013. Disponível em: http://www.revistas.usp.br/ revistadc/article/view/79996/83916. Acesso em 12 de fevereiro de 2019.

https://doi.org/10.11606/issn.1679-9836.v92i3p156-165

LALONDE, Marc. A new perspective on the health of Canadians: a working document. Otawa: Minister of National Health and Welfare, 1974. Disponível em http://www.phacaspc.gc.ca/publications-eng.php. Acesso em 07/01/2019.

LOT, Letícia. Método pilates: 'equilíbrio perfeito entre corpo e mente?'. Monografia de graduação. (Universidade Estadual Paulista 'Júlio de Mesquita Filho'/ Instituto de Biociências - Rio Claro/ Licenciatura em Educação Física). Rio Claro - SP: 2008, $107 f$.

LUZ, Madel Therezinha. É promoção da saúde um novo paradigma? In: LUZ, Madel Therezinha. Ordem social, instituições e políticas de saúde no Brasil: textos reunidos. Rio de Janeiro: CEPESC - IMS/UERJ, 2009, 225p. P. 217-225.

MASSELI, Maria Rita; TURATTI, Talita Ferreira; CRUZ, Cláudio Marcelo da; SILVESTRE, Miriam Rodrigues; PEREIRA, João Domingos Augusto dos Santos. O Shiatsu como terapêutica alternativa em portadores de distúrbios osteomusculares relacionados ao trabalho. Revista Dor. São Paulo SP, vol. 11, n. 3, p. 197-202, jul-set, 2010. Disponivel em: files.bvs.br/upload/S/18060013/2010/v11n3/a1461.pdf. Acesso em 06 de fevereiro de 2019.

NEVES, Selma Cosso. DD.Palmer (1845-1913) e as origens da quiropraxia no século XIX. São Paulo - SP: 2016. Dissertação (Pontifícia Universidade Católica de São Paulo/ Mestrado em História da Ciência). São Paulo - SP, 2016, 77f. Disponível em: https://sapientia.pucsp.br/bitstream/handle/ 19677/Selma\%20Cosso\%20Neves.pdf. Acesso em 05 de janeiro de 2019.

OMS. Estrategia de la OMS sobre medicina tradicional - 2002-2005. Genebra - Suiça: Organização Mundial da Saúde, 2002, 78p. Disponível em: www.apps.who.int/iris/bitstream/ 10665/67314/1/WHO_EDM_TRM_2002.1_spa.pdf. Acesso em 15/06/2017.

OMS. The promotion and development of traditional medicine. Geneva - Switzerland: World Health Organization, 1978, 44p. Disponível em: www.apps.who.int/medicinedocs/dlcuments/ s7147e/s7147e.pdf. Acesso em 15/06/2017.

PAIVA, Geraldo José de. Espiritualidade e qualidade de vida: pesquisas em psicologia. In: TEIXEIRA, Evilázio Francisco Borges; MÜLLER, Marisa Campio; SILVA, Juliana Dors Tigure da (org).

Espiritualidade e qualidade de vida. Porto Alegre - RS: EDIPUCRS, 2004, 243p.

PEREIRA, Martha Priscila Bezerra. O conhecimento geográfico para promoção da saúde. In: Hygeia, vol. 6, n. 10, p. 77-88, junho de 2010. Disponível em: http://www.seer.ufu.br/index. Acessado em 10 de novembro de 2018.

PEREIRA, Martha Priscila Bezerra. Um olhar geográfico sobre as políticas das práticas integrativas e complementares em saúde: possibilidades teórico-metodológicas. Congresso Nacional de Pesquisa e Ensino em Ciências, 3. Anais... Campina Grande - PB: REALIZE, 2018, 12p.

ROSENFELD, Isadore. $O$ guia da medicina alternativa. Rio de Janeiro: Bertrand Brasil, 1999, 333p. SANTOS, Milton. Metamorfose do espaço habitado. 2ed. São Paulo: edusp, 2014, 67p. 
SANTOS, R.V; DA VEIGA, R.A.D.R. Avaliação postural de praticantes da arte marcial Muaythai no município de Erechim - RS. Erechim - RS, Perspectiva, v. 36, n. 133, p. 163-178, março de 2012. Disponível em http://www.uricer.edu.br/site/pdfs/perspectiva/133_261.pdr. Acesso em 06/01/2019.

SIGNIFICADOS. O que é terapia holística. Disponível em www.significados.com.br/terapia-holistica/. Acesso em 30/05/2018.

SILVEIRA, Maycksuel Kayano Santana; MAZZOCCANTE, Rafaello Pinheiro; SOUZA, loanny Castro de; OLHER, Rafael Reis; MENDES, Lucas Vilela; ASANO, Ricardo Yukio; SOTERO, Rafael da Costa. Perda de peso no período pré-competitivo de atletas de judô e jiu-jitsu. Revista Brasileira de Nutrição Esportiva. São Paulo - SP. Vol. 7, n.41, p. 256-262, set/out, 2013.

SOUSA, Valéria da Silva. Um olhar sobre as práticas de cura em Campina Grande: moradores e agentes comunitários em busca de uma racionalidade alternativa em saúde. 53f. 2014. Monografia (graduação). Universidade Federal de Campina Grande/ Unidade Acadêmica de Geografia, Campina Grande, 2014, 62f. Disponível em: www.prosaudegeo.com.br/tcc. Acesso em 17/01/2019.

SOUZA, Marcelo Lopes de. Os conceitos fundamentais da pesquisa sócio-espacial. 2.ed. Rio de Janeiro - RJ: Bertrand Brasil, 2015, 320p.

TARCITANO FILHO, Conrado Mariano; WAISSE, Sílvia. Novas evidências documentais para a história da homeopatia na América Latina: um estudo de caso sobre os vínculos entre Rio de Janeiro e Buenos Aires. História, Ciências, Saúde - Manguinhos, Rio de Janeiro, vol. 23, n. 3, p. 779-798, jul-set, 2016. https://doi.org/10.1590/S0104-59702016005000017

VEIGA, Filipa. Yoga-me: a arte de abrir o coração. Portugal: Nascente, 2016.

VILLAÇA, Flávio. Espaço intra-urbano no Brasil. 2.ed. São Paulo - SP: Studio Nobel/ FAPESP, 2001.

XAVIER, Joab Jefferson da Silva. Equilíbrio em idosos e práticas de Tai Chi Chuan. Ribeirão Preto - SP: 2008. Dissertação (Universidade de São Paulo/ Faculdade de Medicina de Ribeirão Preto/ Mestrado em Ciências Médicas). Ribeirão Preto - SP: 2016, 156f. Disponível em:

www.teses.usp.br/disponiveis/17/17139/tde-06032009-152506/en.php. Acesso em 06/01/2019. 